EXTENDED REPORT

\title{
Treatment of refractory psoriatic arthritis with infliximab: a 12 month observational study of 16 patients
}

\author{
M Feletar, J E Brockbank, C T Schentag, V Lapp, D D Gladman
}

Ann Rheum Dis 2004;63:156-161. doi: 10.1136/ard.2003.006775

\begin{abstract}
See end of article for authors' affiliations

.....................

Correspondence to: Dr D Gladman, Centre for Prognosis Studies in the Rheumatic Diseases, Toronto Western Hospital, ECW 5-034B, 399 Bathurst St, Toronto, Ontario, Canada M5T 2S8; dafna.gladman@ utoronto.ca
\end{abstract}

Accepted 20 May 2003

\begin{abstract}
Objective: To evaluate the effectiveness and toxicity of infliximab in patients with recalcitrant psoriatic arthritis (PsA).

Methods: Patients with treatment resistant PsA and at least six actively inflamed joints, who had failed to respond to at least two disease modifying agents, were included. Infliximab $(5 \mathrm{mg} / \mathrm{kg}$ ) was given at weeks $0,2,6$, and every 6-8 weeks pending response. Clinical and laboratory measures included actively inflamed joint count (AJC), swollen joint count (SJC), psoriasis severity (PASI), HAQ, and SF-36. Response was defined as at least a $30 \%$ reduction in AJC and PASI. Differences from baseline were analysed using the signed rank test.

Results: Sixteen patients ( 12 male, 4 female), mean age 48 and disease duration 14 years, were included. At baseline the mean AJC was 22.5 and mean PASI 4.5. Eleven patients continued receiving methotrexate. The AJC did not show a statistically significant response. SJC improved significantly at week $54(p=0.01)$. The PASI improved significantly at weeks $14(p=0.001)$ and $30(p=0.002)$ and CRP was reduced significantly at week $30(p=0.02)$. The HAQ score improved at week $30(p=0.02)$. Six patients became positive for dsDNA without clinical features of a connective tissue disease. Six patients discontinued treatment owing to lack of efficacy (1) and toxicity (5). Other serious adverse events included: urticaria (3); thrombocytopenia (1); lower gastrointestinal bleeding (2); severe diarrhoea (2); serious infections (6). Raised transaminases, at least $1.5 \times$ normal, occurred in four patients.

Conclusion: In refractory PsA, infliximab led to a marked improvement in psoriasis but modest response in joint disease. Toxicity and rate of treatment termination was high.
\end{abstract}

$\mathrm{P}$ soriatic arthritis (PsA) is an inflammatory arthritis, usually seronegative for rheumatoid factor, associated with psoriasis. ${ }^{1}$ Psoriasis is a common skin disorder, affecting about $1-3 \%$ of the population. Some $7-42 \%$ of patients with psoriasis develop either a peripheral or axial inflammatory arthritis. ${ }^{2}$ Previously understood as a mild disease, PsA is now fittingly recognised as a progressively deforming arthritis associated with significant morbidity. ${ }^{3}$ Until recently there has been little evidence substantiating the efficacy of disease modifying antirheumatic drugs (DMARDs) in PsA and before this era of biological therapy, none had been shown to slow radiological progression in this condition. ${ }^{4}$

The emergent understanding of immunomodulators in inflammatory arthritis has given rise to new therapeutic targets. The role of tumour necrosis factor $\alpha$ (TNF $\alpha)$ in PsA is supported by a number of findings. High levels have been identified in inflamed PsA joints. ${ }^{56}$ Blockade of TNF with infliximab leads to histological improvement in synovial biopsies, which parallels the beneficial effect seen clinically in patients with PsA. ${ }^{7}$ Genetically, allelic variations at the TNF locus influence susceptibility to PsA. ${ }^{8}$ An uncommon TNF polymorphism is strongly associated with HLA-CW*0602, the locus linked to younger age of onset of psoriasis and PsA. ${ }^{9}$ These findings lend support to the rationale for therapeutic use of TNF blockade in PsA. Indeed, three double blind placebo controlled trials using anti-TNF agents have recently been reported. ${ }^{10-12}$

The TNF $\alpha$ receptor blocker, etanercept, in a 12 week double blind randomised trial of 60 patients, was shown to significantly improve arthritis and psoriasis. ${ }^{10}$ The Psoriatic Arthritis Response Criteria (PsARC) ${ }^{13}$ were met by $87 \%$ of treated patients compared with $23 \%$ of those receiving placebo. A further multicentre randomised placebo controlled study of 205 patients demonstrated the efficacy of etanercept using both the American College of Rheumatology 20 (ACR20) response and the PsARC. ${ }^{11}$ Etanercept may also significantly inhibit structural damage and is the first drug to demonstrate this in PsA. ${ }^{14}$

Infliximab is a human/mouse chimeric anti-TNF $\alpha$ antibody that is given parenterally. It has been proved to be effective in the management of rheumatoid arthritis (RA), suppressing symptoms, markers of inflammation, and slowing joint erosion, even in those with minimal improvement in joint symptoms. ${ }^{15} 16$ More recent studies have confirmed this response and have shown further reduction of symptoms with low dose methotrexate. ${ }^{17}$

In PsA, the response to infliximab has been examined in a multicentre randomised controlled trial (RCT), showing efficacy for skin and joints at 16 weeks. ${ }^{12}$ Infliximab was also used in an open fashion in 10 patients and demonstrated improvement in joint symptoms and magnetic resonance imaging changes.$^{18}$ Furthermore, infliximab has been shown to be effective and safe in severe psoriasis alone in a three month trial, leading to histological restoration of normal skin. ${ }^{19}$ Targeted biological therapy by TNF $\alpha$ inhibition

\footnotetext{
Abbreviations: ACR, American College of Rheumatology; AJC, active joint count; ALT, alanine aminotransferase; ANA, antinuclear antibody; AST, aspartate aminotransferase; DMARD, disease modifying antirheumatic drug; dsDNA, double stranded DNA; ELISA, enzyme linked immunosorbent assay; $H A Q$, Health Assessment Questionnaire; NSAIDs, non-steroidal anti-inflammatory drugs; PASI, Psoriasis Area and Severity Index; PsA, psoriatic arthritis; PsARC, Psoriatic Arthritis Response Criteria; RA, rheumatoid arthritis; $R C T$, randomised controlled trial; SF-36, Short Form-36; SJC, swollen joint count; TB, Mycobacterium tuberculosis; TNF $\alpha$, tumour necrosis factor $\alpha$
} 
therefore offers a long awaited new avenue of treatment for this condition.

Although RCTs apply rigorous scientific method to the study of new drugs, they require specific inclusion criteria and may not reflect the spectrum of patients seen in an ambulatory care facility.

The purpose of the current investigation was to evaluate the safety and efficacy of infliximab in both the skin and joint disease of patients whose PsA was resistant to standard treatment in an open label study in an outpatient facility.

\section{PATIENTS AND METHODS \\ Patient selection}

Patients with PsA followed up at the University of Toronto Psoriatic Arthritis Clinic at the Toronto Western Hospital were included. This clinic has been following up patients with PsA prospectively since 1978 and has enrolled over 800 patients, 600 of whom are tracked in a computer database according to a standard protocol for $1-22$ years. Patients with at least six actively inflamed joints (joints demonstrating stress pain and/or swelling) who have failed to respond or shown an incomplete response to standard treatment with non-steroidal anti-inflammatory drugs (NSAIDs) and DMARDs (including methotrexate, azathioprine, sulfasalazine, cyclosporin, antimalarial drugs) were included. Routine toxicity screening was recommended to all patients in this cohort receiving DMARDs, including monthly liver function tests, serum creatinine determination, and full blood count.

Patients continued with their existing DMARD treatment and psoriasis treatment during the trial. Patients who were previously intolerant of methotrexate did not receive this drug. All drug treatment was stable for at least four weeks before the study. Patients with childbearing potential who did not use adequate birth control, patients with functional class 4 , and patients receiving corticosteroid injections within four weeks of the study were excluded. Patients with documented liver disease, and other comorbid conditions, such as pneumonia, hepatitis, and any other serious viral illness, within three months of study were also excluded, as were patients with documented HIV infection or patients with malignancies within the past five years.

\section{Intervention}

Infliximab at $5 \mathrm{mg} / \mathrm{kg}$ was administered by intravenous infusion over two hours initially at weeks $0,2,6$, and 14 . Patients were monitored for one hour after completing each infusion. Subsequent treatment intervals were determined by individual response (5-8 weeks). Infliximab was made available through a special access programme by the company, but no members of the pharmaceutical industry were involved in patient monitoring. The period of observation was 54 weeks.

\section{Clinical measures}

Assessments included actively inflamed joint count (AJC; total of 68 joints) and swollen joint count (SJC; total of 66 joints). We have previously demonstrated that these measures are reliable in our clinic. ${ }^{20}$ Skin disease was evaluated by the Psoriasis Area and Severity Index (PASI), a measure of psoriasis by degree of erythema, induration, and scale, ranked on a scale of $0-4$ and incorporating body surface area affected (head 10\%, trunk 30\%, arms $20 \%$, legs $40 \%$ ). ${ }^{21}$ The maximum possible PASI score is 72 .

These assessments were measured at baseline, 2, 6, 14, 22, $30,38,46$, and 54 weeks just before the infliximab infusion. Quality of life measures were evaluated using the Medical Outcome Survey Short Form-36 (SF-36), ${ }^{22}$ Health Assessment Questionnaire (HAQ), ${ }^{23}{ }^{24}$ and fatigue severity scale, $^{25}$ validated in PsA.
Radiological scoring was performed using the modified Steinbrocker method, validated in PsA. ${ }^{26}$ By this method peripheral joints score 1 for periarticular osteoporosis or nondefinite joint erosions, 2 for erosions, 3 for erosions and joint space narrowing, and 4 for total joint disorganisation, such as joint ankylosis, pencil in cup deformity, or flail joint. Joints scoring 1 were not included in the scoring system. The sacroiliac joints were scored using the New York Criteria. ${ }^{27}$

\section{Laboratory assessments}

Routine laboratory tests (haematology and biochemistry) were performed at each visit. Serological tests, including antinuclear antibodies (ANAs) and anti-double stranded DNA (dsDNA) antibodies were measured at baseline and during treatment. The ANAs were tested using the Hep-2 cell preparation with a titre of $\geqslant 1 / 160$ considered positive. The dsDNA antibodies were measured by both enzyme linked immunosorbent assay (ELISA) and the Farr assay.

\section{Response measures}

Two primary outcomes were evaluated: (a) joint disease: a reduction of the actively inflamed joint count by $>30 \%$ of baseline values was considered improvement; $(b)$ skin disease: a reduction in the PASI score of $>30 \%$ was considered improvement. Patients not completing 54 weeks of treatment owing to either lack of efficacy or toxicity were considered non-responders. All adverse events were recorded and evaluated as secondary measures.

\section{Analysis}

The data were described using means (standard deviations) and proportions. The signed rank test was used to determine if the mean paired difference from baseline was significantly different from zero. A p value of 0.05 was considered significant.

\section{RESULTS}

\section{Patient characteristics}

Between September 2000 and March 2001, 16 patients were included in the study. As documented in table 1, these patients were non-responsive to existing treatment and had active skin and joint disease. Detailed radiological information before infliximab treatment was available in 15 of 16 patients. All patients had been treated with methotrexate in the past and 11 patients continued this during infliximab treatment. The other five had discontinued methotrexate treatment because of side effects (4) or lack of efficacy (1). Information on past methotrexate doses was available in 15 patients. The mean cumulative dose in these 15 was $2352 \mathrm{mg}$.

The five patients who were not receiving methotrexate at the start of the study had a mean past DMARD use of 2.8 drugs and at the time of this study one was receiving chloroquine and the remaining four were taking no DMARDs.

\section{Clinical and laboratory response}

For the primary end points, it was found that a $30 \%$ reduction in the AJC was achieved by 7 (44\%), 4 (25\%), and $3(19 \%)$ patients, at weeks 14, 30, and 54, respectively (table 2). A $30 \%$ reduction in PASI was achieved by $9(56 \%), 9(56 \%)$, and $7(44 \%)$, at weeks 14, 30, and 54, respectively. A 30\% reduction in SJC was achieved by $9(56 \%), 8(50 \%)$, and 7 (44)\%, at weeks 14,30 , and 54, respectively. The raw data (table 3 ) show that the AJC did not show a statistically significant improvement at any time. The SJC showed a significant improvement at week $54(\mathrm{p}=0.01)$. The PASI improved significantly at weeks $14(\mathrm{p}=0.001)$ and 30 $(\mathrm{p}=0.002)$, and the $\mathrm{C}$ reactive protein $(\mathrm{CRP})$ was reduced significantly at week 30 . 
Table 1 Demographic features of 16 patients with psoriatic arthritis at baseline

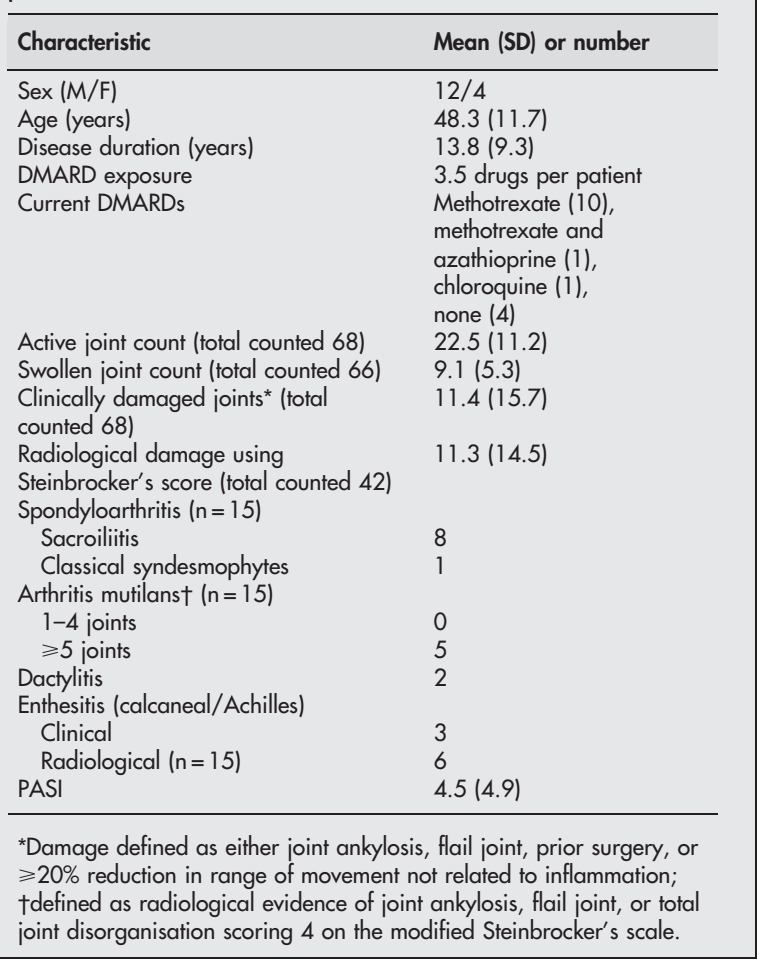

The domains evaluating quality of life, including the composite score for the HAQ, the SF-36, fatigue severity scale, patient visual analogue scale for skin severity, stiffness, and pain did not show statistically significant improvement.

Six of our patients did not respond well to $5 \mathrm{mg} / \mathrm{kg}$ infliximab at eight week intervals and required more frequent infusions at intervals of six weeks or less. Five of these patients demonstrated a response to infliximab but experienced recurring joint symptoms about six weeks after each infusion and therefore benefited from more frequent infusions at 5-6 week intervals. One patient (patient 3) showed only a moderate response to eight-weekly infusions, thus more frequent infusions were attempted to gain greater benefit, but this was not achieved.

\section{Treatment discontinuation and toxicity}

Six $(38 \%)$ patients did not complete 54 weeks of treatment with infliximab. In these patients the mean time to discontinuation (last infliximab infusion) was 24.5 weeks. Reasons for discontinuation included liver toxicity (3), severe allergic reaction (1), lack of efficacy and allergic reaction (1), and lack of efficacy alone (1).

Of the three patients discontinuing owing to liver toxicity, two were concomitantly treated with methotrexate. Patient 1 developed high transaminases (alanine aminotransferase (ALT) $141 \mathrm{U} / \mathrm{l}$, normal $<68$; aspartate aminotransferase (AST) $50 \mathrm{U} / \mathrm{l}$, normal $<40$ ) at week 6 . Infliximab was stopped and methotrexate taken concurrently at a dose of $25 \mathrm{mg}$ intramuscularly was continued. The transaminases became normal over the following months. At the start of the study, the AST and ALT were normal. Three months before the study only the ALT was raised at $86 \mathrm{U} / \mathrm{l}$, but spontaneously normalised. Alcohol intake was 2-3 standard drinks a week. This patient also had persistent lower gastrointestinal bleeding and diarrhoea after the third infusion, but had a history of colonic polyps. Prior methotrexate exposure included a mean dose of $25 \mathrm{mg} /$ week for 42 months. Patient 2 developed a transaminitis which peaked at week
Table 2 Response measures for active joints, swollen joints, and PASI score in 16 patients with psoriatic arthritis treated with infliximab

\begin{tabular}{lllll}
\hline \multicolumn{5}{c}{ Weeks } \\
\cline { 2 - 5 } \cline { 3 - 4 } & \% Reduction & 14 & 30 & 54 \\
\hline Active joints & 30 & $7(44)$ & $4(25)$ & $3(19)$ \\
& 50 & $4(25)$ & $3(19)$ & $3(19)$ \\
Swollen joints & 70 & $1(6)$ & $1(6)$ & $1(6)$ \\
& 30 & $9(56)$ & $8(50)$ & $7(44)$ \\
PASI & 50 & $9(56)$ & $5(31)$ & $7(44)$ \\
& 70 & $7(44)$ & $3(19)$ & $4(25)$ \\
Discontinuations & 30 & $9(56)$ & $9(56)$ & $7(44)$ \\
& 50 & $6(38)$ & $6(38)$ & $5(31)$ \\
& 70 & $1(6)$ & $1(6)$ & $1(6)$ \\
& & $1(6)$ & $3(19)$ & $6(38)$ \\
\hline
\end{tabular}

17, AST $434 \mathrm{U} / \mathrm{l}($ normal $<40)$, alkaline phosphatase $148 \mathrm{U} / \mathrm{l}$ (normal $<110$ ). This patient was also receiving methotrexate $25 \mathrm{mg}$ intramuscularly. Methotrexate and infliximab were stopped at this time. Transaminases normalised within four weeks, and a liver biopsy was not carried out. Alcohol intake was significant at 4-5 standard drinks/day. An ultrasound disclosed an enlarged fatty liver. Viral hepatitis serology was negative. Infliximab doses were administered again at weeks 25 and 29, without methotrexate, but an urticarial reaction occurred, which was treated with antihistamines. Treatment was stopped at week 29, after six infusions in view of these cumulative problems. The mean methotrexate dose had been $20 \mathrm{mg}$ for 43 months before study onset and before this occurrence liver function had been normal. Patient 3 developed a transaminitis leading to cessation of treatment at week 24 (ALT $150 \mathrm{U} / \mathrm{l}$, AST $59 \mathrm{U} / \mathrm{l}$ ). Liver function subsequently rapidly normalised. The patient was not receiving concomitant methotrexate and clinical response had been poor.

Patient 4 discontinued at week 12 owing to a combination of problems, which included mild allergic symptoms (rash with mild chest discomfort), an episode of epididymitis (testicular pain and swelling resolving with antibiotics), liver toxicity, and insufficient clinical response. Transaminitis occurred at week 6 (ALT $97 \mathrm{U} / \mathrm{l}$, AST $40 \mathrm{U} / \mathrm{l}$ ) and normalised at week 12, while methotrexate was continued. The patient was receiving methotrexate $25 \mathrm{mg}$ parenterally at the time and past exposure included a mean dose of $20 \mathrm{mg} / \mathrm{week}$ for 48 months before the study onset. Patient 5 was receiving methotrexate $20 \mathrm{mg} /$ week and discontinued infliximab after experiencing a severe allergic reaction at week 37, with urticarial rash, chest tightness, and dyspnoea. Allergic symptoms first occurred during the previous infusion. Patient 6 discontinued at week 39 owing to lack of efficacy without toxicity. A response occurred at week 22 but was not sustained. The patient was not receiving methotrexate because of previous intolerance.

Other adverse events were common (table 4). Liver toxicity (transaminases $>1.5 \times$ normal) occurred in four male patients in total, three leading to discontinuation as described above. The fourth patient (patient 7 ) had slowly rising transaminases peaking at week 32 (ALT $111 \mathrm{U} / \mathrm{l}$, AST $69 \mathrm{U} / \mathrm{l}$ ). These normalised over four months and the infliximab was continued. This patient was not receiving methotrexate at the time and did not have a history of liver disease. Prior methotrexate was taken at a mean dose of $10.8 \mathrm{mg} /$ week for 35 months, which included 12 months of treatment 10 years previously and 23 months of treatment which stopped 30 months before starting infliximab. Side effects leading to stopping treatment included mucositis, chronic chest infections, and abdominal symptoms. 
Table 3 Mean reduction from baseline in clinical, laboratory, and quality of life measures in 16 patients with psoriatic arthritis treated with infliximab

\begin{tabular}{|c|c|c|c|c|c|c|c|c|c|}
\hline \multirow[b]{2}{*}{ Item } & \multicolumn{3}{|c|}{14 Weeks } & \multicolumn{3}{|c|}{30 Weeks } & \multicolumn{3}{|c|}{54 Weeks } \\
\hline & $\mathbf{n}$ & $\begin{array}{l}\text { Mean difference } \\
\text { (SD) }\end{array}$ & pł & $\mathbf{n}$ & $\begin{array}{l}\text { Mean difference } \\
\text { (SD) }\end{array}$ & pł & $n$ & $\begin{array}{l}\text { Mean difference } \\
\text { (SD) }\end{array}$ & $\mathrm{p} \ddagger$ \\
\hline Tender joints* & 15 & $-2.7(2.8)$ & 0.30 & 13 & $0.6(2.8)$ & 0.98 & 9 & $-1.8(3.8)$ & 0.67 \\
\hline Swollen joints* & 15 & $-2.5(1.3)$ & 0.09 & 13 & $-2.5(2.0)$ & 0.09 & 9 & $-5.0(1.4)$ & 0.01 \\
\hline $\mathrm{PASI}^{*}$ & 15 & $-3.5(1.2)$ & 0.001 & 10 & $-1.5(0.4)$ & 0.002 & 3 & $0.9(1.7)$ & 1.00 \\
\hline $\mathrm{CRP}^{*}$ & 14 & $-13.4(8.6)$ & 0.01 & 11 & $-7.7(3.1)$ & 0.02 & 6 & $-7.5(4.6)$ & 0.22 \\
\hline $\mathrm{HAQ}^{*}$ & 10 & $-0.2(0.5)$ & 0.38 & 9 & $0.3(0.4)$ & 0.02 & 7 & $-0.4(0.4)$ & 0.06 \\
\hline HAQ skin* & 10 & $-0.2(0.5)$ & 0.21 & 9 & $0.3(0.3)$ & 0.008 & 7 & $-0.41(0.3)$ & 0.03 \\
\hline \multicolumn{10}{|l|}{ SF-36t } \\
\hline PCS & 9 & $0.4(9.7)$ & 0.91 & 6 & $2.2(5.5)$ & 0.68 & 7 & $4.4(5.2)$ & 0.08 \\
\hline MCS & 9 & $4.3(7.3)$ & 0.13 & 6 & $2.5(4.8)$ & 0.31 & 7 & $0.4(7.8)$ & 0.94 \\
\hline $\mathrm{BP}$ & 10 & $4.1(19.6)$ & 0.56 & 6 & 4.7 (15.8) & 0.87 & 7 & $20.3(19.0)$ & 0.02 \\
\hline
\end{tabular}

*Negative numbers indicate improvement; positive numbers "deterioration"; †positive numbers indicate improvement; negative numbers "deterioration"; $\neq \mathrm{p}$ value for the sign rank test used to test the mean (paired) difference is zero.

PCS, physical component summary; MCS, mental component summary; BP, bodily pain domain.

All infections reported had not been previously experienced by the patients. Septic arthritis occurred in a diabetic female patient. The two patients with pneumonia had chest radiographic bronchopneumonic changes and were treated successfully orally without admission to hospital. Epididymitis and perichondritis were unusual events in two patients. Testicular pain and hydrocele, managed without antibiotics, settled spontaneously in another patient. One patient experienced a surgical site abscess developing in a finger, at a site of operation performed two years previously. Most of these infections occurred within three months of the start of treatment.

Allergic reactions involving urticaria, with or without respiratory symptoms, occurred in three $(19 \%)$ patients, all of whom were receiving methotrexate. Lower gastrointestinal bleeding, self limiting, occurred in two patients, one with a history of colonic polyps. Thrombocytopenia developed in one patient with a fluctuating mild platelet reduction (100$\left.150 \times 10^{9} / 1\right)$ throughout the 12 month period. The lower limit reached during this time was $102 \times 10^{9} / 1$. After the study period while the patient continued infliximab the platelet count fell to $62 \times 10^{9} / 1$ at 15 months, at which time a bone marrow biopsy was performed and found to be normal.

Serologically, four patients were ANA positive at baseline. Eight of the $12(75 \%)$ negative at baseline became ANA positive during the study, five of whom were receiving methotrexate. Six patients became positive for anti-dsDNA during the study (three Farr only, one Farr and ELISA, two ELISA only). Three of these were receiving methotrexate. No clinical features of a connective tissue disease developed in any of the patients during this period of observation.

\section{DISCUSSION}

This open label study of 16 patients with PsA treated with infliximab demonstrated high toxicity and a high discontinuation rate in an outpatient facility. It must be noted that highly refractory disease, with significant joint damage and a high degree of past DMARD use, distinguishes our cohort from others in open label reports to date and indeed may have contributed to our poorer results in comparison with these other groups. In addition, where the treatment interval was prolonged owing to an intercurrent infection, joint and skin assessments would probably have deteriorated. This would tend to underestimate the treatment response because no evaluations were made between infusions. Moreover, we elected to present our results based on an intention to treat model. However, if we looked at response rates of the 10 patients completing the trial, the response in the swollen joint count at 54 weeks is improved, with $88 \%$ of patients achieving a $50 \%$ response and $50 \%$ of patients achieving a $70 \%$ response.

Reported information about the use of infliximab in PsA comes from one RCT and other open label studies. The only published randomised trial to date examining the efficacy of infliximab in PsA, the Infliximab Multinational Psoriatic Arthritis Controlled Trial (IMPACT), included 102 patients and demonstrated positive results using infliximab $(5 \mathrm{mg} / \mathrm{kg})$ versus placebo in patients with at least five swollen joints, over 16 weeks. ${ }^{12}$ Stable dose DMARDs were permitted as

\begin{tabular}{|c|c|}
\hline Toxicities (number of patients) & Details (number of patients) \\
\hline Infections (6) & $\begin{array}{l}\text { Pneumonia (2), septic arthritis (1), surgical site abscess (1), perichondritis (1), } \\
\text { epididymitis (1) }\end{array}$ \\
\hline Hepatic (4) & Transaminases $>1.5 \times$ normal $(4)$, concomitant MTX treatment (2) \\
\hline Gl-other than hepatic (3) & $\begin{array}{l}\text { Lower gastrointestinal bleeding (2) } \\
\text { Diarrhoea (2) }\end{array}$ \\
\hline Allergic (3) & Urticaria (3), respiratory symptoms (2) \\
\hline Haematological (1) & Thrombocytopenia (platelets $102 \times 10^{9} /$ ) \\
\hline \multirow[t]{4}{*}{ Serological (9) } & ANA seroconversion ( $8 / 12$ seronegative at onset) \\
\hline & Anti-dsDNA seroconversion (6) \\
\hline & ANA and dsDNA seroconversion (5) \\
\hline & No clinical evidence of a connective tissue disease was seen \\
\hline Other (1) & Hydrocele \\
\hline
\end{tabular}


concomitant treatment. Patients achieving ACR20, ACR50, and ACR70, numbered $70.6 \%, 52.9 \%$, and $25.5 \%$, respectively. Complications included one case of septic arthritis in the treatment group. No infusion reactions occurred and the discontinuation rate was $3.9 \%$. These patients had used fewer DMARDs before infliximab and their disease might not have been as recalcitrant as in our patients.

Other reports of infliximab in PsA are confined to open label studies. Antoni et al reported on the open label treatment of 10 patients with polyarticular PsA with infliximab, who continued to receive stable dose NSAIDs, DMARDs (seven methotrexate), and corticosteroids. ${ }^{18}$ A dose of $5 \mathrm{mg} / \mathrm{kg}$ was used at weeks 0,2 , and 6 , followed by the lower dose of $3 \mathrm{mg} / \mathrm{kg}$ thereafter, modified by patient response. Therapeutic efficacy was sustained, with all patients achieving ACR50 and Clegg response criteria at week 54. Eight patients at week 54 had no tender or swollen joints. Magnetic resonance imaging showed a mean reduction of gadolinium uptake in affected joints of $82 \%$ in eight patients scanned. Psoriasis also significantly improved. One patient discontinued owing to a mild infusion reaction and pregnancy. No serious adverse events occurred. A significant difference of this cohort compared with ours, is the much younger age of the subjects (mean age 34.8 years $v 48.3$ in our study). The concurrent doses of methotrexate and details of past DMARD use were also not elaborated.

Cauza et al reported treatment of nine patients with PsA with infliximab over 22 weeks, receiving five infusions at the lower dose of $3 \mathrm{mg} / \mathrm{kg} .{ }^{27}$ Eight patients completed the study. Response was rapid and sustained in most for the observation period and treatment well tolerated, with no serious adverse events reported. In contrast with our study, concurrent DMARDs were not used and past DMARD exposure was again not clearly elaborated. Inclusion criteria were not stated, rather nine consecutive patients were included, and the pattern of disease and radiological damage was not defined. Significantly, the mean age of the patients was high at 57.3.

Other case reports of infliximab in PsA include much smaller numbers of patients. ${ }^{28-30}$

Thus in comparing our cohort with the aforementioned reports, the demographic and clinical details of our patients clearly delineate them as a refractory group, and hence they represent a distinct subset with severe polyarticular disease.

Experience gained with infliximab in the broader spondyloarthropathy population has also contributed valuable information. Infliximab used in a group of mixed patients with spondyloarthropathy, some of whom have PsA, has shown benefit in both an $\mathrm{RCT}^{31}$ and an open label ${ }^{32}$ study. Toxicity however, included one case of Mycobacterium tuberculosis (TB) in a patient with PsA and a case of septic arthritis in a patient with spondyloarthropathy.

$\mathrm{RCT}^{33}$ and open label ${ }^{34}{ }^{35}$ studies of infliximab in ankylosing spondylitis (AS) have shown benefit but with major toxicity seen. Two of 35 patients in the RCT developed serious complications, including one case of allergic granulomatosis of the lung and another of systemic TB. Mild leucopenia was seen in one patient, leading to withdrawal. Maksymowych et al found in an open label study in AS that one patient each developed osteomyelitis and severe hypersensitivity, and only $8 / 21$ completed one year of treatment. ${ }^{34}$

In our experience, infections were common, but no TB was detected. The one case of septic arthritis occurred in a woman with the additional predisposing factor of diabetes. Perichondritis and a digital surgical site abscess, developing years after the surgery, occurred in patients with no other comorbidities, however. Such complications were not previously experienced by these patients. Experience in the broader spondyloarthropathy population illustrates the potential for immunosuppression with unusual and severe infections occurring after infliximab treatment and is a major concern. Certainly, in the RA population, post-marketing surveillance information has highlighted the increased risk of TB and opportunistic infections with this drug, and open label studies will continue to contribute information about these complications.

Although to date hepatic toxicity has not been found to be a significant problem with infliximab in RA or PsA, transaminitis was common in our group of patients. Notably, all four patients who had transaminases 1.5 times normal were male and methotrexate was used in only two, one of whom also had a significant alcohol intake. One of these patients had had stable liver function during the long previous history of methotrexate use and the other had had some rise in ALT before infliximab use, which normalised before trial onset. Other trials in which methotrexate was used concomitantly with infliximab ${ }^{12}{ }^{18}$ did not report this complication. Kruithof et al in the mixed spondyloarthropathy population, however, found that AST and ALT rose significantly during the treatment period of 54 weeks, but remained in the normal range. ${ }^{32}$ Widespread use of infliximab in RA has shown that hepatic toxicity is not a major concern, however. Differences in the pathophysiology of RA and spondyloarthropathy, may produce a dissimilar DMARD toxicity profile, so direct extrapolation of safety information from the RA literature may not be appropriate. This is highlighted by a meta-analysis of studies looking at methotrexate hepatotoxicity in liver biopsies in patients with RA and PsA, which found that patients with psoriasis are more prone to liver toxicity than those with RA. ${ }^{36}$ Possibly, however, in our uniquely reported older cohort of patients with severe, refractory disease, the occurrence of liver disturbance is higher, perhaps contributed to by the combination of methotrexate and infliximab or infliximab alone.

A significant number in this series became ANA or dsDNA positive. Results from previous series have been variable and serology was not always recorded. Kruithof et al reported 12/ $21(57 \%)$ developing ANA, four of whom also developed antidsDNA antibodies. ${ }^{32}$ Maksymowych et al found that none of their 21 patients with AS became ANA or anti-dsDNA positive during the open label AS trial. ${ }^{34}$ Both infliximab and etanercept have been implicated in the development of lupus-like syndromes in patients with RA being treated with these agents, justifying close observation of those patients seroconverting. ${ }^{37-39}$

\section{CONCLUSION}

In this open label study of 16 patients with refractory PsA and active skin and joint disease, infliximab was shown to be effective in psoriasis with lesser benefit in PsA. Toxicity was a major concern. Conclusions about the efficacy of infliximab in PsA cannot be derived from this experience.

The evidence for TNF blockade in PsA is the most convincing to date in support of DMARD use in this condition and provides the first evidence of radiological protection. Information both from RCTs and open label studies such as this will contribute valuable information about the usefulness of these relatively new agents.

\section{ACKNOWLEDGEMENTS}

The authors' acknowledge the help of Schering Canada in obtaining access to infliximab for their patients.

\footnotetext{
Authors' affiliations

M Feletar, J E Brockbank, C T Schentag, V Lapp, University of Toronto Psoriatic Arthritis Clinic, Toronto Western Hospital, Toronto, Canada D D Gladman, University of Toronto Psoriatic Arthritis Clinic, Centre for Prognosis Studies in the Rheumatic Diseases, Toronto Western Hospital, Toronto, Canada
} 


\section{REFERENCES}

1 Gladman DD, Rahman P. Psoriatic arthritis. In: Ruddy S, Harris ED, Sledge CB, Budd RC, Sergent JS, eds. Kelly's textbook of rheumatology, 6th ed. Philadelphia: Saunders, 2001:1071-9.

2 O'Neill TO, Silman AJ. Psoriatic arthritis: historical background and epidemiology. Baillieres Clin Rheumatol 1994;8:245-61.

3 Gladman DD. Psoriatic arthritis [review]. Rheum Dis Clin North Am 1998;24:829-44.

4 Brockbank J, Gladman D. Diagnosis and management of psoriatic arthritis. Drugs 2002;62:2447-57.

5 Partsch G, Steiner G, Leeb BF, Dunky A, Broll H, Smolen JS. Highly increased levels of tumor necrosis factor-alpha and other proinflammatory cytokines in psoriatic arthritis synovial fluid. J Rheumatol 1997;24:518-23.

6 Ritchlin C, Haas-Smith SA, Hicks D, Cappuccio J, Osterland CK, Looney RJ. Patterns of cytokine production in psoriatic synovium. J Rheumatol 1998;25:1544-52.

7 Baeten D, Kruithof E, Van den Bosch F, Demetter P, Van Damme N, Cuvelier C, et al. Immunomodulatory effects of anti-tumor necrosis factor alpha therapy on synovium in spondyloarthropathy. Histologic findings in eight patients from an open-label pilot study. Arthritis Rheum 2001;44:186-95

8 Hohler T, Grossman S, Stradmann-Bellinghausen B, Kaluza W, Reuss E, de Vlam K, et al. Differential association of polymorphisms in the TNFalpha region with psoriatic arthritis but not psoriasis. Ann Rheum Dis 2002:61:213-18.

9 Al-Heresh AM, Proctor J, Jones SM, Dixey J, Cox B, Welsh K, et al. Tumour necrosis factor-alpha polymorphism and the HLA-Cw*0602 allele in psoriatic arthritis. Rheumatology (Oxford) 2002;41:525-30.

10 Mease PJ, Goffe BS, Metz J, VanderStoep A, Finck B, Burge DJ. Etanercept in the treatment of psoriatic arthritis and psoriasis: a randomized trial. Lancet 2000;356:385-90.

11 Mease P, Kivitz A, Burch F, Siegel E, Cohen S, Burge D. Improvement in disease activity in patients with psoriatic arthritis receiving etanercep $\left(\right.$ Enbrel $\left.^{\boxplus}\right)$ : results of a phase 3 multicenter clinical trial [abstract]. Arthritis Rheum 2001;44(suppl 9):S90.

12 Antoni C, Kavanaugh A, Kirkham B, Burmester G, Weisman M, Keystone E, et al. The infliximab multinational psoriatic arthritis controlled trial (IMPACT) [abstract]. Arthritis Rheum 2002;46(suppl 9):S985.

13 Clegg DO, Reda DJ, Abdellatif ML. Comparison of sulfasalazine and placebo for the treatment of axial and peripheral articular manifestations of the seronegative spondyloarthropathies. A Department of Veterans Affairs cooperative study. Arthritis Rheum 1999:42:2325-9.

14 Ory P, Sharp JT, Salonen D, Rubenstein J, Mease PJ, Kivitz AJ, et al. Etanercept (Enbrel ${ }^{\boxplus}$ ) inhibits radiographic progression in patients with psoriatic arthritis [abstract]. Arthritis Rheum 2002;46(suppl 9):S442.

15 Elliott MJ, Maini RN, Feldmann M, Kaldman JR, Antoni C, Smolen JS, et al Randomised double-blind comparison of chimeric monoclonal antibody to tumour necrosis factor alpha (cA2) versus placebo in rheumatoid arthritis. Lancet 1994;344:1105-10.

16 Lipsky PE, van der Heijde DM, St Clair EW, Furst DE, Breedveld FC, Kalden JR, et al. Infliximab and methotrexate in the treatment of rheumatoid arthritis. Anti-Tumor Necrosis Factor Trial in Rheumatoid Arthritis with Concomitant Therapy Study Group. N Engl J Med 2000;343:1594-602.

17 Maini RN, Breedveld FC, Kalden JR, Smolen JS, Davis D, Macfarlane JD, et al. Therapeutic efficacy of multiple intravenous infusions of anti-fumour necrosis factor alpha monoclonal antibody combined with low-dose weekly methotrexate in rheumatoid arthritis. Arthritis Rheum 1998;41:1552-63.

18 Antoni C, Dechant C, Hanns-Martin Lorenz PD, Wendler J, Ogilvie A, Lueftl $M$, et al. Open-label study of infliximab treatment for psoriatic arthritis: clinical and magnetic resonance imaging measurements of reduction of inflammation. Arthritis Rheum 2002;47:506-12.

19 Chaudhari U, Romano P, Mulcahy LD, Dooley LT, Baker DG, Gottlieb AB. Efficacy and safety of infliximab monotherapy for plaque-type psoriasis: a randomised trial. Lancet 2001;357:1842-7.

20 Gladman DD. Psoriatic arthritis [review]. Curr Opin Rheumatol 1990;2:577-81

21 Fredriksson T, Pettersson U. Severe psoriasis-oral therapy with a new retinoid. Dermatologica 1978;157:238-44.

22 Husted J, Gladman DD, Long JA, Farewell VT, Cook R. Validating the SF-36 health questionnaire in patients with Psoriatic Arthritis. J Rheumatol 1997;24:511-17

23 Husted J, Gladman DD, Farewell V, Long J. Modified HAQ in psoriatic arthritis. Clin Exp Rheumatol 1995:13:439-44.

24 Blackmore M, Gladman DD, Husted J, Long J, Farewell VT. Measuring health status in psoriatic arthritis: the Health Assessment Questionnaire and its modification. J Rheumatol 1995;22:886-93.

25 Schentag CT, Beaton M, Rahman P, Husted J, Gladman DD. Fatigue in psoriatic arthritis (PsA). J Rheumatol 1999:26:1627.

26 Rahman P, Gladman DD, Cook RJ, Zhou Y, Young G, Salonen D. Radiological assessment in psoriatic arthritis. Br J Rheumatol 1998;37:760-5.

27 Cauza E, Spak M, Cauza K, Hanusch-Enserer U, Dunky A, Wagner E. Treatment of psoriatic arthritis and psoriasis vulgaris with the tumor necrosis factor inhibitor infliximab. Rheumatol Int 2002;22:227-32.

28 Wollina U, Konrad $\mathrm{H}$. Treatment of recalcitrant psoriatic arthritis with antitumor necrosis factor-alpha antibody. J Eur Acad Dermatol Venereol 2002;16:127-9.

29 O'Quinn RP, Miller JL. The effectiveness of tumor necrosis factor alpha antibody (infliximab) in treating recalcitrant psoriasis: a report of 2 cases. Arch Dermatol 2002;138:644-8.

30 Schopf RE, Aust H, Knop J. Treatment of psoriasis with the chimeric monoclonal antibody against tumor necrosis factor alpha, infliximab. J Am Acad Dermatol 2002;46:886-91.

31 Van den Bosch F, Kruithof E, Baeten D, Herssens A, De Keyser F, Mielants H, et al. Randomized double-blind comparison of chimeric monoclonal antibody to tumor necrosis factor $\alpha$ (infliximab) versus placebo in active spondyloarthropathy. Arthritis Rheum 2002:46:755-65.

32 Kruithof E, Van den Bosch F, Baeten D, Herssens A, De Keyser F, Mielants H, et al. Repeated infusions of infliximab, a chimeric anti-TNF alpha monoclonal antibody, in patients with active spondyloarthropathy: one year follow up. Ann Rheum Dis 2002:61:207-12.

33 Braun J, Brandt J, Listing J, Zink A, Alten R, Golder W, et al. Treatment of active AS with infliximab: a randomized controlled multicentre trial. Lancet 2002;359: 1187-93.

34 Maksymowych WP, Jhangri GS, Lambert RG, Mallon C, Buenviaje $\mathrm{H}_{\text {, }}$ Pedrycz $\mathrm{E}$, et al. Infliximab in ankylosing spondylitis: a prospective observational inception cohort analysis of efficacy and safety. J Rheumato 2002;29:959-64.

35 Stone M, Salonen D, Lax M, Payne U, Lapp V, Inman R. Clinical and imaging correlates of response to treatment with infliximab in patients with ankylosing spondylitis. J Rheumatol 2001;28:1605-14

36 Whiting-O'Keefe QE, Fye KH, Sack KD. Methotrexate and histologic hepatic abnormalities: a meta-analysis. Am J Med 1991;90:711-16.

37 Shakoor N, Michalska M, Harris CA, Block JA. Drug-induced systemic lupus erythematosus associated with etanercept therapy. Lancet 2002;359:579-80.

38 Ali Y, Shah S. Infliximab-induced systemic lupus erythematosus. Ann Intern Med 2002; 137:625-6.

39 Favalli EG, Sinigaglia L, Varenna M, Arnoldi C. Drug-induced lupus following treatment with infliximab in rheumatoid arthritis. Lupus 2002;11:753-5. 